\title{
Limitações e inconsistências das definições sintéticas para psicologia
}

\author{
Limitations and inconsistencies of synthetic definitions for psychology
}

\author{
William Barbosa Gomes \\ Universidade Federal do Rio Grande do Sul \\ Brasil
}

\begin{abstract}
Resumo
O objetivo deste memorandum é a proposição de uma definição conceitual para a psicologia capaz de integrar desdobramentos de objetos, diferenças entre métodos, e variedades de aplicações. O argumento baseia-se no fato óbvio de que existe apenas um psiquismo, mesmo que se reconheça diferentes modos de descrevê-lo, estudá-lo, preveni-lo e tratá-lo. Desde modo, a psicologia pode ser definida como um vasto campo de manifestações impressivas e expressivas as quais podem ser sintetizadas em articulações de suas propriedades afetivas, cognitivas e conativas, podendo tais manifestações serem observáveis (perspectiva de terceira pessoa) ou não (perspectiva de primeira pessoa). Os termos do enunciado serão definidos e discutidos após análise lógica e histórica de definições apresentadas por filósofos e psicólogos, do final do século XIX ao início do século XXI. A proposição assenta-se na esclarecedora diferenciação entre pluralidade de objetos (hierarquia ontológica ou desdobramentos de objetos) e pluralismo de concepções (diversidade epistemológica).
\end{abstract}

Palavras-chaves: campo da psicologia; unidade da psicologia; definição de psicologia.

\begin{abstract}
The purpose of this memorandum is to propose a conceptual definition for psychology capable of integrating unfolding objects, methodological differences and application diversity. The argument is based on the obvious fact that there is only one psyche, even if one recognizes different ways of describing, studying, preventing and treating it. Thus, psychology can be defined as a vast field of impressive and expressive manifestations which can be synthesized in articulations of their affective, cognitive and conative properties, and such manifestations can be observable (third-person perspective) or not (firstperson perspective). The enunciation terms will be discussed after logical and historical analysis on definitions presented by philosophers and psychologists, from the end of the 19th century to the beginning of the 21th century. The proposition is based on the clarifying differentiation between plurality of objects (ontological hierarchy or unfolding of objects) and pluralism of conceptions (epistemological diversity).
\end{abstract}

Keywords: psychology field; psychology unit; psychology definition. 
O que é psicologia? O que aparentemente ensejaria uma resposta breve e objetiva, trata-se de questão complexa, podendo facilitar, dificultar, ou enviesar a compreensão da grande área e de suas subáreas. Pode ainda inibir ou encobrir a utilização de poderosos e consolidados recursos que a ciência psicológica, em seu conjunto, oferece aos profissionais. Na consulta aos manuais introdutórios recentes, a resposta ao que é psicologia será simples e em poucas palavras, mas com poucas chances de esclarecer o que é psicologia. Na consulta a dicionários de psicologia ou mesmo vernaculares, a resposta será complexa e em muitas palavras, mas com melhores chances de esclarecer as relações entre a grande área e as subáreas. O problema da definição parece estar associado a escolhas conceituais. Uma prática comum é da definição por exclusão de partes, seja por diferenciação de probabilidades (quantitativa) ou possibilidades (qualitativa), mas esse caminho não parece promissor porque é epistemológico. Outro modo de exclusão seria por conteúdos, onde o foco estaria em diferenciar o que seria ou não o objeto da psicologia. Contudo, o que tem prevalecido é abrir o leque ontológico, apesar das disputas entre níveis, e assegurar a pertinência pela cientificidade dos métodos. Desse modo, conforme a escolha que se faça, a psicologia pode ser uma ou várias. Tal versatilidade ou ambiguidade pode ser esclarecida quando se distingue a pluralidade de objetos que compõem um campo de conhecimento (relações entre níveis ontológicos) de pluralismo de concepções (perspectivas e variações epistemológicas) (Ballantyne, 1993). Do mesmo modo, a escolha poderá acompanhar Sigmund Koch (1917-1996) e entender que a psicologia é uma coletânea de diversos e diferentes estudos e intervenções (Koch, 1969), ou acompanhar Carl Jung (1875-1961) na pergunta (Jung, 1958/1991, p. 59): "Já que somente existe um psiquismo humano, não deveria existir tão somente uma psicologia?".

O objetivo deste memorandum é analisar diferentes definições de psicologia. A análise toma como ponto de partida a economia das definições atuais para apontar suas incoerências lógicas, tendo como pano de fundo anotações históricas sobre definições de psicologia. O breve estudo destina-se especialmente a professores com a nobre e elevada função de introduzir a psicologia para as novas gerações de estudantes universitários ou para aqueles com curiosidade de saber o que é psicologia. Certamente, não se apresentará aqui uma definição definitiva, mas uma definição que possa propiciar uma visão mais abrangente, coerente e profícua desta ciência e profissão. O estudo conclui com a ênfase de que a psicologia é uma ciência sui generis, cuja posição no campo geral do conhecimento ocupa o único nível ontológico que interliga os níveis ontológicos simbiótico ou semiótico (níveis interacional, social e cultural) com os níveis não simbólicos 
(psicobiológicos e psicofísicos). É nesta privilegiada inter-relação que está a especificidade da grande e fundamental ciência da psicologia.

\section{A definição sintética de psicologia}

Wilhelm Wundt (1832-1920) inicia o seu célebre Grundrisse der Psychologie (Elementos de Psicologia) discutindo a definição de psicologia (Wundt, 1896/1897). Ele se referia a duas definições que eram proeminentes na época: 1) ciência da mente; 2) ciência da experiência interior. Contudo, na avaliação dele nenhuma das duas definições seriam satisfatórias. Restringir psicologia à mente, embora a aproxime das ciências humanas, poderia obscurecer suas inerentes relações com as ciências naturais. Por outro lado, restringir psicologia à experiência interior, embora aborde facetas relevantes do funcionamento psíquico, como os sentimentos, a vontade, e as decisões, excluiria a experiência exterior. A experiência traz em si conteúdos exteriores objetivos que são apreensíveis pelo sujeito que os experiencia. Wundt não chega a propor uma definição que resolva as dicotomias das duas definições discutidas, limitando-se a ressaltar a necessidade da pesquisa empírica para a ciência psicológica.

Certamente, diante da dificuldade de definir psicologia, antigos manuais introdutórios preferiram descrever as atividades do psicólogo, e não definir diretamente o que é psicologia. Waclaw Radecki (1887-1953), um dos primeiros doutores com formação europeia a vir para o Brasil, disse ser difícil encontrar uma definição sintética para psicologia. Tais dificuldades decorriam das constantes e progressivas mudanças de objeto, e da abrangência e variedade de métodos. Contudo, ele comparou duas definições para mostrar a grande mudança de concepção entre o final do século XIX e o início do século XX. Assim, cita um Dicionário Filosófico publicado em 1880, no qual Paul Janet (1823-1899) define psicologia como "uma parte da filosofia que trata da alma e de suas faculdades, consideradas em si mesmas e por intermédio exclusivo da consciência" (Janet, 1880, citado por Radecki, 1933, p. 5). Em contraste, em seu curso de psicologia na Universidade de Genebra, Radecki anotara do seu professor Théodore Flournoy (1854-1920) que psicologia era "uma ciência natural, particular, que trata dos fenômenos da consciência, em relação com todos os demais e por meio de todos os métodos possíveis" (Flournoy, s.d., citado por Radecki, 1933, p. 5). O contraste entre as duas definições mostra aspectos históricos notórios. A definição de Janet carrega as influências da psicologia das faculdades de Christian Wolff (1679-1754), hoje reconhecida como precursora da psicologia científica (Araújo, 2020). Já a definição de Flournoy reflete as posições de Wundt, sendo enfático no 
reconhecimento da psicologia como ciência natural, tendo como objeto central o estudo dos fenômenos da consciência e suas "relações com todos os demais" (Radecki, 1933, p. 5) o que pode ser entendido como a indicação da pluralidade do objeto. Tais objetos poderiam ser estudados "por meio de todos os métodos possíveis" (Radecki, 1933, p. 5), o que seria pluralismo de concepções. Sabe-se que Flournoy, em sua passagem por Leipzig, acompanhou as aulas de Wundt e se considerava seu discípulo (Alvarado, 2015).

O mesmo problema defrontado por Radecki constava em dois manuais introdutórios muito utilizados no Brasil, tempos depois. Tratam-se dos manuais de Krech e Crutchfield (1958/1963) e Davidoff (1987/2001). O manual de Krech e Crutchfield (Elementos de Psicologia) foi muito elogiado por oferecer uma visão integrada do campo psicológico. Do mesmo modo que Radecki (1933), Krech e Crutchfield, dois renomados psicólogos sociais experimentais, muito influenciados por um dos precursores da psicologia cognitiva, Edward C. Tolman (1886-1959), optaram por não definir psicologia. Eles preferiram descrever o artifício científico usado pelos psicólogos para estudar a pessoa. Assim, não se privilegiou a definição da ciência, mas os critérios de investigação. Os autores enfatizaram que o interesse se dirigia para a pessoa, por eles definida como um organismo total que não pode ser segmentado em partes, pois tal conduta comprometeria o conjunto, a unidade. Para eles, "a pessoa total é, positivamente, grande demais para ser tratada por qualquer cientista, com instrumentos e conceitos ora disponíveis" (Krech e Crutchfield, 1958/1963, p. 3). No entanto, eles defenderam que sem perder a noção de conjunto, de unidade, este todo teria que ser decomposto em partes, pois este é o artifício científico. O "Elementos de Psicologia" de Krech e Crutchfield (1958/1963) foi saudado em revisão no Psychoanalytic Quarterly (Posinsky, 1958) e recomendado a professores de orientação psicodinâmica que porventura viessem a lecionar disciplinas introdutórias. Para o autor, Krech e Crutchfield apresentavam os fenômenos psicológicos como manifestações articuladas e coordenadas, evitando a segmentação em capítulos desconectados, o que veio a predominar nos manuais introdutórios de psicologia. Mesmo um manual publicado em espanhol pela União Soviética (Petrovski, 1985), encontrado em livrarias brasileiras nos inícios dos anos 1990, reconhecia a dificuldade da definição de psicologia, limitando-se a informar que o objeto seria "os atos concretos da vida psíquica caracterizados qualitativa e quantitativamente" (p. 23).

Com o decorrer do tempo, a definição de psicologia que veio a se consagrar foi realmente muito sintética. O manual introdutório de Linda L. Davidoff (1987/2001), muito utilizado nos anos 1990s e 2000s definiu a psicologia como "a ciência que se concentra no comportamento e nos processos mentais" (p. 6). 
Contudo, a autora alertava para a complexidade de se definir uma grande área, com tantas subáreas. Ela seguiu na mesma linha de Koch (1969) para dizer que seria mais razoável definir a grande área como estudos psicológicos e não como uma ciência. Em contraste, Blair-Broeker e Ernest (2019) em seu atrativo e ilustrado manual, Thinking about Psychology, complementaram o título com: The science of mind and behavior. Os autores assumiram, sem percalços, a definição sintética, reafirmando o termo ciência.

O APA Dictionary (VandenBos, 2015) foi cauteloso em suas duas definições sintéticas. Na primeira, psicologia foi definida como o estudo da mente e do comportamento. $\mathrm{Na}$ segunda, psicologia foi definida como a presumível combinação de comportamentos, estilos e atitudes que caracterizam um indivíduo ou um grupo. Na primeira definição, o termo 'estudo' substituiu o termo 'ciência', o que pode ser interpretado como influência das observações de Koch (1969, 1992). Na segunda, o termo 'presumível' descreve o entendimento geral e difuso do que poderia ser chamado de psicologia popular, referindo-se a esses conhecimentos sobre pessoas e nós mesmos que todos temos com maior ou menor clareza. Como se sabe, psicologia é o termo usado pelas pessoas em geral para descrever e referir a características, traços, reações, estilos e peculiaridades de si e de outros, o que tem sido imortalizado na literatura, no teatro, na dança, no cinema e em contos, romances e comédias. Neste sentido, Wilhelm Dilthey (18331911) já dizia que dramas como "Lear, Hamlet e Macbeth de [William] Shakespeare [1564-1616] contêm mais psicologia que todos os livros de psicologia juntos" (Dilthey, 1894/1977, p. 36). Do mesmo modo, Friedrich Nietzsche (1844$1900)$ referiu-se ao escritor russo Fiódor Dostoievski (1821-1881) como "o único psicólogo de quem se tem algo a aprender" (Nietzsche, 1889/2001, p. 89). Inclusive, aventa-se a possibilidade de textos de Dostoievski terem influenciado conceitos posteriormente formalizados na psicanálise, como repressão e a relação entre desconforto psíquico e as narrativas de sonhos (Pavlovic \& Pavlovic, 2012; Rancour-Laferrière, 1989). O próprio Wundt (1912/1916) reconheceu que o desenvolvimento psicológico não se limitava aos efeitos do físico (externo) no psíquico (interno), pois a consciência manifesta-se ao mundo a partir de suas vivências. Para ele o estudo dessa expressividade estava além dos métodos experimentais, exigindo a compreensão da cultura, da linguagem, das artes, dos mitos e dos costumes, ao que veio a chamar de Völkerpsychologie (psicologia do povo). O APA Dictionary completou a definição informando que a psicologia é um campo diversificado em muitas subáreas, que utiliza grande variedade de métodos de pesquisa, cujos resultados são empregados com êxito em vários aspectos da vida social, ecológica, econômica e individual. 


\section{Problemas da definição sintética de psicologia}

Para Henriques (2004), a definição sintética de psicologia como o estudo da mente e do comportamento é contraditória. O autor justifica sua posição comparando as descrições dos verbetes mente e comportamento no Webster's Unabridged Dictionary (1994), quando referentes à psicologia. No Webster's, 'mente' refere-se tanto à totalidade dos processos mentais conscientes e inconscientes, como a totalidade das atividades de um organismo. Já 'comportamento' refere-se as respostas observáveis do organismo em suas interrelações, sendo que qualquer destas respostas pode ser considerada como objeto da psicologia. Na análise de Henriques (2004), as definições de mente e comportamento não funcionam como aspectos complementares, mas como paradoxo por serem simultaneamente includentes e excludentes. Elas são includentes quando se referem à 'totalidade ou ao conjunto das atividades de um organismo.' São excludentes quando distinguem o não observável (processos mentais) do observável (comportamentos). Na perspectiva do autor do presente artigo, a conciliação entre os dois enunciados poderia ser a seguinte: psicologia é o estudo da mente e/ou do comportamento. Na prática, é o que ocorre com correntes teóricas que se dedicam: 1) 'ou' ao estudo da mente; 2) 'ou' ao estudo do comportamento, 3) 'ou' ao estudo da mente 'e' do comportamento. Tem-se, então, uma solução de diferenciação por exclusão, cuja fórmula lógica é a seguinte: $\{$ ou [ou...ou] ou [e....e]\}, isto é \{ou [mente ou comportamento] ou [mente e comportamento]\}. A proposição de Henriques (2004) era chegar a uma definição de psicologia capaz de integrar ou se referir apropriadamente a perspectiva de terceira e de primeira pessoa. Ter-se-ia uma diferenciação por combinação inclusiva, cuja fórmula lógica é a seguinte $\{e$ [e...e] e [ou...ou]\}, que com a aposição dos termos ficaria \{e [mente e comportamento] e [mente ou comportamento]. Para Henriques (2004) a definição de psicologia deve abarcar dois domínios: aquele do comportamento animal que corresponde aos processos psicológicos básicos, e aquele do comportamento humano que corresponde a uma interface entre os processos psicológicos básicos e os processos psicossociais.

O historiador e psicólogo Ernest R. Hilgard (1904-2001) foi crítico a proposições teóricas que desconsideravam a unidade das três propriedades essenciais do funcionamento psicológico: afeição, cognição e conação (Hilgard, 1980). Por afeição entende-se a força que anima e que move o animal humano e não humano. Manifesta-se em sensações, sentimentos, humores e emoções que impulsionam ou reagem a toda e qualquer atividade e circunstância, podendo ir 
do sofrimento à alegria, do desânimo ao entusiasmo, da ternura à raiva, da passividade à agressividade, ou reversivamente. Por cognição entendem-se todos os processos de conhecimento e consciência tais como percepção, atenção, imaginação, memória, pensamento, julgamento e inteligência. Por conação, entende-se a conexão entre o afetivo e o cognitivo manifesto na conjunção unitária descrita como impressividade (senso receptor) e expressividade (senso emissor). A literatura em psicologia refere-se à conação como a condição proativa do comportamento, em oposição ao reativo ou habitual (VandenBos, 2015). A descrição do termo oferecida pela semiótica (Nöth, 1990) pode ser mais instrutiva, por incluir a dimensão comunicacional do comportamento, diferenciando emissor voluntário ou involuntário, receptor voluntário ou involuntário, e situação. Daí derivam-se as contingências e implicações morais e éticas do comportamento, pois as manifestações diretas, indiretas ou mesmo circunstanciais do emissor sempre afetam receptores em torno, sejam os de destino ou não, o mesmo ocorrendo com o receptor. O termo semiótica foi introduzido na filosofia por John Locke (16321704) para denominar o estudo comunicacional dos signos ou sistemas de sinais (Nöth, 1990).

Historicamente, a classificação tripartida referida por Hilgard (1980) foi central para a teoria alemã das faculdades mentais (segunda metade do século XVIII), foi preservada na psicologia associacionista britânica (primeira metade do século XIX), foi segmentada pelas psicologias experimentais ou fisiológicas (segunda metade do século XIX), foi subjacente nas teorias do inconsciente (primeira metade do século XX), foi desprezada nas teorias behavioristas (primeira metade do século $X X$ ), e foi retomada nas teorias cognitivas (inícios do século XXI). Em qualquer época, cultura ou viés, uma teoria psicológica terá necessariamente que tomar uma destas três propriedades como primeiro plano, permanecendo as demais como plano de fundo. Em outras palavras, essas teorias assumem que intervir experimental ou experiencialmente em uma propriedade é suficiente para alterar as demais. Obviamente, cada propriedade pode e deve ser estudada em suas partes e subpartes, mas o conjunto não pode ser desprezado. No entanto, essa visão integrada do campo psicológico ainda parece longe de ser alcançada. Em suma, tratam-se de propriedades imprescindíveis, por serem geradoras e mediadoras das atividades conscientes ou inconscientes, impressivas e expressivas, voluntárias ou involuntárias, condicionadas ou incondicionadas.

\section{Diferenças entre conteúdo e estrutura no funcionamento psicológico}


A ambiguidade entre pluralidade de objetos e pluralismo de concepções está no maior ou menor entendimento do conceito de ontologia pelos proponentes e defensores de teorias e autores. O termo ontologia refere-se à definição de objetos e à hierarquia relacional que os constitui. A ontologia pode ser realista, definindo objetos concretos, ou pode ser conceitual, definindo ideias ou ficções (Bunge, 1987). Marsh e Boag (2014) revisaram o uso do conceito de ontologia em 31 artigos, procedentes de três periódicos muito bem avaliados, todos publicados em 2012: Psychological Bulletin (Vol. 38 No. 2), Psychological Review (Vol. 23, No. 7), e Psychological Science (Vol. 23, No. 7). Os autores concluíram que o termo foi usado de modo vago, confuso ou mesmo contraditório. Embora se reconheça certa arbitrariedade na delimitação ontológica, sua estrutura deve estar claramente definida e justificada. A justificação é a tarefa da epistemologia na explicação e comprovação de como e do porquê se sabe. A ambiguidade está na problemática relação entre ideia e fato, onde o pluralismo de concepções pode encobrir a pluralidade de objetos (Gomes, 2021).

Certamente, a maior dificuldade para definir o campo da psicologia está na não diferenciação das duas faces ontológicas: conteúdo e estrutura. O foco imediato tem sido em conteúdo como percepção, consciência, sentimentos, inconsciente, memória, associações, aprendizagem, comportamento, nem sempre conferindo a devida atenção à estrutura do funcionamento mental em sua amplitude e ações. Milton (2010) mostrou que a maneira mais efetiva de apresentar e definir um campo é pela delimitação de sua estrutura. Por estrutura, entende-se a disposição relativamente estável de elementos ou componentes serem organizados como um todo (VandenBos, 2015). Esta organização se compõe de uma rede de relações hierárquicas constituídas por grandezas decomponíveis em partes, mantendo as relações entre elas e o todo (Lanigan, 1992). A disposição relativamente estável concede à estrutura e aos seus níveis hierárquicos um estatuto ontológico, cujas relações são reguladas por leis ou conjunto de leis. Assim, implica em ordem ou configuração, e em interatividade e desenvolvimento. Por conseguinte, estrutura é uma concepção bidirecional, composta da forma estática que a constitui, e do processo dinâmico que a anima. $\mathrm{Na}$ prática, estrutura pode ser entendida como um sistema ou um conjunto de subsistemas, podendo ser descrita na constante de sua forma e na dinâmica de seus processos que são as hierarquias relacionais (Lanigan, 1992). Operacionalmente, conteúdos são entendimentos conceituais que podem mudar com avanços da ciência e com as práticas culturais, enquanto estrutura permanece como a unidade de referência. Assume-se, portanto, que a natureza humana, enquanto estrutura, é universal, a-histórica, atemporal, caracterizando de modo 
genérico todos os humanos como seres ativos, falantes, racionais, com capacitação potencial para acesso direto e indireto ao que é dado, para construções de sentidos e crenças, e para o exercício da vontade.

A semiótica (Petocz, 2011) oferece recursos para uma configuração do campo psicológico, sendo capaz de preservar a unidade e não inibir a diversidade. Para o autor, há um enorme entrelaçamento entre os campos da psicologia e da semiótica, sendo que uma aproximação traria benefícios aos dois campos. 0 praticalismo científico não crítico e a confusão metateórica têm inibido a aproximação entre psicologia e semiótica. Radicalismo científico, negativismo científico, seleção de objetos ou exclusão de objetos podem empobrecer as perspectivas de terceira e primeira pessoa, comprometendo a visão unitária do campo psicológico e a compreensão da pessoa como um todo. Assim, tomando a estrutura como um esquema ou mapa, organizado por correlatos semióticos, podese chegar à configuração didática do campo psicológico e abrir caminho para uma definição inclusiva. É o que sugere a Figura 1.

\begin{tabular}{|c|c|c|c|c|c|}
\hline $\begin{array}{c}\text { Linhas } \\
1\end{array}$ & \multicolumn{2}{|c|}{$\begin{array}{l}\text { Segundo Correlato } \\
\text { Objeto (afeição) } \\
\text { (Nutritivo/sensitivo) }\end{array}$} & \multicolumn{2}{|c|}{$\begin{array}{l}\text { Primeiro Correlato } \\
\text { Representamen (cognição) } \\
\text { (Intelectivo) }\end{array}$} & $\begin{array}{l}\text { Terceiro Correlato } \\
\text { Interpretante } \\
\text { (conação) } \\
\text { (Responsividade) }\end{array}$ \\
\hline 2 & Símbolo & & \multicolumn{2}{|c|}{$\begin{array}{l}\text { Psicologia como ciência humana } \\
\text { Agência (Self) }\end{array}$} & \multirow{3}{*}{ Comportamento } \\
\hline \multirow[t]{2}{*}{3} & Experiência & Percepção & $\begin{array}{c}\text { Racional } \\
\text { Consciência }\end{array}$ & Imaginação & \\
\hline & & Afeição & Irracional & $\begin{array}{l}\text { Memória/Hábito } \\
\text { (Inconsciente) }\end{array}$ & \\
\hline 4 & $\begin{array}{l}\text { Ambiente } \\
\text { (Estímulo) }\end{array}$ & \multicolumn{3}{|c|}{$\begin{array}{c}\text { Corpo } \\
\text { (Organismo) } \\
\text { Psicologia como ciência natural }\end{array}$} & $\begin{array}{r}\text { Adaptação } \\
\text { (Resposta) }\end{array}$ \\
\hline
\end{tabular}

Figura 1 - Correlação semiótica entre as três propriedades psicológicas de afeição, cognição e conação

A Figura 1 segue a lógica triádica da semiótica de Charles S. Peirce (18391914) e está organizada pelas simetrias conceituais entre linhas e colunas, conforme Gomes $(2017,2019)$. Os termos que encabeçam as colunas (Linha 1) são da semiótica de Peirce (1931-1958, parágrafos 2.233-71).

Os termos semióticos empregados são sugestivos e provisórios, cuja ideia é delimitar estruturas independentes de conteúdos. Também, observe-se que a descrição se refere ao que é dado para percepção e para ação. Assim, por objeto entende-se a aquiescência perceptual de algo qualquer; por representamen o 
objeto perceptível enquanto sentido e entendimento, e por interpretante os efeitos do entendimento que se manifestam com maior ou menor racionalidade na resposta a si ou ao outro. Por correlato semiótico entenda-se a conversão recíproca entre sistemas que se integram em diversas e diferentes propriedades, considerados correlacionais quando funcionam como 'ou esse ou aquele' (ou...ou), e relacionais quando funcionam como 'e esse e aquele' (e...e). Portanto, a Linha 1 indica o funcionamento operacional cognoscente, explicitado pelas funções que compõem as respectivas colunas. O posicionamento das colunas orientou-se pela história da psicologia, na relação entre experiência, consciência e comportamento da tradição filosófica; na relação estímulo (experiência), consciência e resposta na psicofísica; e na relação entre estímulo, organismo e adaptação no funcionalismo. No entanto, há entre as colunas uma relação de liberdade e arbitrariedade, dependendo da perspectiva ou da tradição considerada. No caso da semiótica, o primeiro correlato ocupou a posição central para manter coerência com a tradição histórica da psicologia.

Prosseguindo com a descrição da Figura 1, passa-se ao exame das tríades horizontais subsequentes (linhas). O sequenciamento obedece a historicidade e justifica a ordem referencial das Linhas. Daí a necessidade de iniciar pela Linha 3 que traz a tríade experiência - consciência - comportamento. Essa tríade está associada à filosofia moderna, mas já estava presente na antiga filosofia grega e na filosofia medieval, servindo de base para a teorização em psicologia moderna desde o século XVIII. Foi o ponto de partida para a psicologia experimental ou fisiológica de Wundt, para a psicologia descritiva de Franz Brentano (1838-1917), e para a fenomenologia de Edmund Husserl (1859-1938). Ambas as teorias tiveram como foco central a experiência consciente. Na Linha 4 encontra-se a tríade ambiente - corpo - adaptação que foi consolidada pela teoria da evolução, e foi base do funcionalismo, do behaviorismo, da psicanálise, da epistemologia genética, e do cognitivismo. A tríade reflete a posição dos funcionalistas em definir a psicologia como uma ciência natural. Na Linha 2 está a tríade símbolo - agência - linguagem que sintetiza as influências do romantismo e da arte literária, do existencialismo, do estruturalismo e da psicanálise francesa, sendo dominante nas ciências humanas. A ordem das linhas também indica para as possíveis reduções descendentes (ambiente, organismo e resposta) e ascendentes (símbolo, agência e linguagem). Assim, tem-se na posição ascendente um reducionismo (upward reduction) pró ciências humanas e na posição descendente um reducionismo (downward reduction) pró ciências naturais.

A comparação dos termos que compõem as Colunas aponta para uma impressionante simetria entre eles. A Coluna referente ao objeto (segundo 
correlato) mostra a conexão entre experiência, ambiente e símbolo. Experiência é um conceito amplo e de uso comum, mas raramente definido em recentes manuais de psicologia. James (1890/1981, p. 461) nos ensinou que

A experiência, desde o início, nos apresenta objetos concretos, vagamente contínuos com o resto do mundo que os envolve no espaço e no tempo, e potencialmente divisíveis em elementos e partes interiores.

Por experiência nós entendemos tanto a apreensão da realidade por um agente cognoscente, como uma história de vida, um modo de agir e o vivencial presente. Da experiência procede a compreensão do que é dado como real ou abstrato, podendo ser influenciado pela memória e pela reflexão. Daí circunscrevermos a condição de subjetividade ao apreensível pela pessoa. $O$ interessante no conceito de experiência é a sua relação imediata com o conceito de experimento que é a indução controlada para alguma ação, ou seja, produção controlada de experiências. Em outras palavras, humanos e não humanos vivem envolvidos na experiência que é intrinsecamente relacionada ao ambiente, à memória (Wundt, 1896/1897), e aos valores agregados aqui indicados como símbolos (Nöth, 1990). A mesma conexão ocorre entre a Coluna referente ao representamen (primeiro correlato), onde tem-se a consciência, a corporeidade (logo abaixo), e a função precípua de fazer sentido e interpretar, que é capacitação reflexiva humana, a condição de escolha ou julgamento (agência, self). A simetria do interpretante (terceiro correlato) está no desfecho do ato psicológico em si, que é a ação em palavras, gestos ou respostas (comportamentos). O termo conação indica que as ações voluntárias ou involuntárias implicam em consequências para si, para o outro ou para o ambiente. O termo adaptação pode ser entendido tanto na sua definição estrita, isto é, ajuste sensorial à intensidade ou qualidade da estimulação; como na sua definição evolucionária, isto é, a capacitação para conviver ou mesmo transformar o ambiente. Foi pela conação que se chegou as primeiras demandas à psicologia aplicada, pois os sintomas sejam aqueles vivenciados por alguém (mal-estar, melancolia) ou observados por alguém (transtornos da percepção e do pensamento, dificuldades de aprendizagem, delinquência) são manifestações conativas e comunicacionais.

Entre as Linhas e Colunas estão indicados alguns processos essenciais ao funcionamento psicológico. Os afetos se expressam pelo humor e por qualquer interferência na ação e no pensamento. Os afetos dirigem ou são mobilizados: 1) pela percepção que viabiliza o contato com o mundo real, integrando e interpretando a informação sensorial; 2) pela imaginação que elabora o abstrato 
com indicações para suas possíveis realizações, e 3) pelas tomadas de decisão e julgamentos. A memória com sua força associativa é o grande sustentáculo da vida psíquica, mantendo presente o sentido de si e do mundo, sendo ainda a depositária e dinamizadora das associações inconscientes. O hábito é a capacitação para coordenar e automatizar ações e pensamentos, um recurso de economia mental. Na Coluna referente ao representamen têm-se ainda o contraste entre o racional, que é o pensamento lógico, e o irracional que atua por lógica própria e por automatismos. Nesta breve descrição, a transparência de unidade estrutural é autoevidente.

Tradicionalmente, as teorias trabalharam com conteúdos indicados nas Colunas da Figura 1 com uma semiótica correlacional, ou esse ou aquele; quando poderiam trabalhar com uma semiótica relacional, e esse e aquele. Aí está a base da desconexão e desunidade entre segmentos teóricos da psicologia. No entanto, a visão unitária da psicologia tem que ser considerada com cautela. O trabalho científico é parcimonioso, trabalhando com a seleção e a exclusão de partes (ou...ou), explorando todas as possibilidades e avançando com base em comprovações continuadamente revistas. Por outro lado, o trabalho científico também conta, na atualidade, com recursos de inclusão (e...e), podendo abordar conjuntos molares. A prática estimulou a competição entre pesquisadores que privilegiam determinados conteúdos como o objeto da psicologia (consciência, intencionalidade, percepção, inconsciente, comportamento, memória, aprendizagem, e mais recentemente o cérebro). Constata-se, então, que o campo da psicologia é composto por uma pluralidade de objetos que são considerados por diferentes perspectivas, teorizações e métodos. É neste sentido que Krech e Crutchfield (1958/1963) referiram-se à unidade da pessoa que pode ser decomposta em partes, ou em subáreas como afirmou Davidoff (1987/2001). Ressalta-se que a unidade de campo é real, estando a desunidade em escolhas mal definidas ou mal-entendidas (a relação entre as partes - ontologia) ou mal concebidas e justificadas (diferentes perspectivas entre as partes - epistemologia) (Gomes, 2021)

Na verdade, a inovação da Figura 1 está na síntese configurativa que oferece, podendo também ser interpretada como um mapa conceitual. As distinções apontadas pelas linhas 2, 3, e 4 aparecem com clareza em livros de história da psicologia como Wolman (1981) e Figueiredo (1991), e na análise sociossemiótica de Wiley (1994). Wolman foi um dos primeiros a apresentar uma história da psicologia abrangente, incluindo as tradicionais vertentes experimentalistas e as vertentes humanistas, com atenção ao pensamento de Immanuel Kant (17241804) e Wilhelm Dilthey. Figueiredo trouxe um elegante apanhado definido como 
matrizes conceituais da psicologia, das quais eu destacaria, para a presente discussão, a descrição das matrizes funcionalistas, ambientalistas e compreensivistas. O autor foi além das distinções, destacando interacionismos entre matrizes que seriam justificadas pela impossibilidade de sustentar uma explicação excludente para os fenômenos vitais. Trata-se do reconhecimento da coordenação necessária entre o ambiente interno e externo dos seres vivos. Esse interacionismo, aponta o autor, é muito claro, por exemplo, na psicanálise de Sigmund Freud (1856-1939) na psicologia genética de Jean Piaget (1896-1980), e no behaviorismo de B. F. Skinner (1904-1990). Apesar dos fortes argumentos e evidências sobre o interacionismo, os reducionismos resistem e podem vir de ambos os extremos como indicado por Wiley (1994). Os extremos são definidos nas linhas 2 (redução ascendente) e 4 (redução descendente) que corresponderiam às reduções subjetivistas e objetivistas.

\section{Proposição de uma definição integrada para a psicologia}

Diante do exposto, a psicologia pode ser definida como um vasto campo de manifestações impressivas e expressivas as quais podem ser sintetizadas em articulações de suas propriedades afetivas, cognitivas e conativas, podendo tais manifestações serem observáveis (perspectiva de terceira pessoa) ou recolhidas de autorrelatos (perspectiva de primeira pessoa). Estas manifestações caracterizam a vida humana e, observando o gradiente diferencial, a vida de animais não humanos. Para os humanos, tais manifestações podem ser representadas em ficção, poesia, teatro, drama, dança, cinema, pintura e música, podendo ser analisadas por critérios literários, políticos ou discursivos. As manifestações psicológicas constituem dados empíricos que são passíveis de experimentação em laboratórios e em campo, levantamentos por questionários ou por entrevistas, e autorrelatos. O diferencial da psicologia no campo geral do conhecimento está no domínio da articulação interacional entre afeto, cognição e conação. Teorias que não têm clareza desta articulação denotam contextos empobrecidos, pois a função de uma teoria é demarcar um contexto para julgamento. A distinção entre estrutura e conteúdo oferece uma nova visão da unidade em psicologia, capaz de reconhecer a pluralidade de objetos e de se servir do pluralismo de métodos e concepções.

Dois termos incluídos na definição requerem explicações: impressivo e expressivo. A escolha de palavras para compor uma definição é sempre problemática e traiçoeira, dados os muitos significados associados a um verbete tanto no uso geral como no uso particular. Com efeito, o vocabulário da psicologia 
se confunde com o vernacular de senso comum e com termos técnicos de outras áreas, dificultando a compreensão precisa. Mesmo entre teorias psicológicas há diferenças quanto a definição de termos. Assim, por manifestações impressivas entende-se a subjetividade temporal que guia cada aspecto do comportamento e cognição, distinguindo memória, percepção e antecipação (Arstila \& Lloyd, 2014). Por sua vez, por manifestações expressivas entende-se a objetividade espaçotemporal de um organismo em movimentos gestuais de qualidades diferenciadas que podem ser observados, medidos e associados a determinados antecedentes ou consequentes. No entanto, o mais interessante na conjunção impressivoexpressivo é a unidade na articulação entre recepção-emissão, também entendida como percepção e ação.

Independente das grandes questões teóricas, o campo científico e profissional da psicologia reúne estudos robustos capazes de compreender, explicar, predizer e até controlar ações humanas (Stanovich, 2013). Esses estudos constituem um corpo de conhecimento que pode facilitar a compreensão de comportamentos humanos e comportamentos animais, e saber o que influencia ou mesmo determina modos humanos de pensar e agir. Contudo, reconheceu Stanovich, poucos profissionais dominam esses conhecimentos tão importantes e necessários ao bem-estar individual e coletivo. Essa situação poderia mudar se déssemos mais atenção aos fundamentos históricos da psicologia e a unidade do campo psicológico, como defendeu Justo (1987) em seu pequeno, mas esclarecedor, estudo sobre a identidade de psicólogo.

\section{Conclusão}

A proposição uma definição ampla que faça justiça ao campo da psicologia está baseada na diferenciação entre conteúdo e estrutura, não se tratando de uma teoria para substituir outras, ou para inibir a diversidade de pensamento e pesquisa. O compromisso é com uma descrição que faça justiça à complexidade do campo e a riqueza de seus métodos. Tampouco se alinha com reducionismos às neurociências e às ciências comportamentais como propôs Melchert (2016) nem à centralidade da experiência e aos métodos qualitativos como propôs Valsiner (2009). A ideia é clarificar as dimensões do campo em um mapa semiótico no qual teorias sobre aspectos psicológicos possam ser localizadas quanto aos seus posicionamentos e compreendidas em suas especificidades e inter-relações. 0 grande objetivo foi enfatizar a noção de campo psicológico composto por variados e distintos aspectos do psiquismo humano e animal, e como esse psiquismo pode ser compreendido em sua totalidade funcional. 


\section{Referências}

Alvarado, C. S. (2015). Théodore Flournoy. Em Psi Encyclopedia. The Society for Psychical Research. Recuperado em 03 de março, 2021, de https://psiencyclopedia.spr.ac.uk/articles/theodore-flournoy.

Araújo, S. F. (2020). A ideia de uma ciência da alma: Christian Wolff e o surgimento da psicologia científica na Alemanha. Doispontos, 17(1), 44-51. Recuperado em 24 de novembro, 2021, de http://dx.doi.org 10.5380/dp.v17i1.74871.

Arstila, V. \& Lloyd, D. (Eds.). (2014). Subjective time: the philosophy, psychology, and neuroscience of temporality. Cambridge, MA; Londres: The Mit Press.

Ballantyne, P. F. (1993). Unity and diversity of subject matter or pluralism? Em Annual Meeting of Cheiron, 24st. New Hampshire: USA. Recuperado em 02 de abril, 2019, de http://www.comnet.ca/\%7Epballan/Unityvsplural.html.

Behavior (1994). Em Webster's Encyclopedic Unabridged Dictionary of the English Language (p. 168). Bexley, OH: Gramercy Books.

Blair-Broeker, C. \& Ernest, R. M. (2019). Thinking about psychology: The science of mind and behavior. Worth Publishers.

Bunge, M. (1987). Epistemologia: Curso de Atualização (C. Navarra, Trad.). São Paulo: EDUSP (Original em espanhol publicado em 1980)

Davidoff, L. L. (1987). Introduction to psychology. NY: McGraw-Hill Publishing.

Davidoff, L. L. (2001). Introdução à psicologia (L. Perez, Trad.). São Paulo: Pearson Education.

Dilthey, W. (1977). Descriptive psychology and historical understanding (R. M. Zaner \& K. L. Heiges, Trads.). Haia: Martins Nijhoff. (Original publicado em alemão em 1894).

Figueiredo, L. C. M. (1991). Matrizes do pensamento psicológico. Petrópolis, RJ: Vozes

Gomes, W. B. (2017). How can "the play of signs and the signs of play" become an attractive model for dealing with eidetic and empirical research? Semiotics, 37, 1-19. Recuperado em 24 de novembro, 2021, de https://doi.org/10.5840/cpsem20173.

Gomes, W. B. (2019). Looking in history for novel integrated view on psychological science and method. Em S. H. Koller. (Org.). Psychology in Brazil: Scientists 
making a difference (pp. 167-193). Cham, Suíça: Springer International Publishing, https://doi.org/10.1007/978-3-030-11336-0 10.

Gomes, W. (2021). Pluralidade de objeto versus pluralismo de concepções em teorias psicológicas. Memorandum, 38, 1-29. Recuperado em 24 de novembro, 2021, de https://doi.org/10.35699/1676-1669.2021.25462.

Henriques, G. R. (2004). Defining Psychology. Journal of Clinical Psychology, 60(10), 1207-1221. Recuperado em 24 de novembro, 2021, de https://doi.org/10.1002/jclp.20061.

Hilgard, E. R. (1980). A trilogy of mind: Cognition, affection, and conation. Journal of History of Behavioural Sciences, 16, 107-177. Recuperado em 24 de novembro, 2021, de https://doi.org/10.1002/15206696(198004)16:2<107::AID-JHBS2300160202>3.0.CO;2-Y.

James, W. (1981). The principles of Psychology. Cambridge, MA: Harvard University Press. (Original publicado em 1890).

Jung, C. G. (1981). A prática da psicoterapia (M. L. Orth, Trad.). Petrópolis, RJ: Vozes. (Original publicado em alemão em 1958).

Justo, H. (1987). Identidade do psicólogo. Canoas, RS: La Salle.

Koch S. (1969). Psychology cannot be a coherent science. Psychology Today, 3, 64-68.

Koch, S. (1992). The nature and limits of psychological knowledge: Lessons of a century qua "science". Em S. Koch \& D. E. Leary, D. E. (Eds.). A century of psychology as science (pp. 7-35). Washington, DC: APA.

Krech, D. \& Crutchfield, R. S. (1958). Elements of psychology. NY: Alfred A. Knopf, Inc. [Em português, Elementos de psicologia [D. M. Leite \& M. L. M. Leite, Trads.). Pioneira, 1963].

Krech, D. \& Crutchfield, R. S. (1963). Elementos de Psicologia (D. M. Leite \& M. L. M. Leite, Trads.) São Paulo: Pioneira.

Lanigan, R. (1992). The human science of Communicology. Pittsburgh, PA: Duquesne University Press.

Marsh, T. \& Boag, S. (2014). Unifying psychology: Shared ontology and the continuum of practical assumptions. Rev Gen Psychol, 18(1), 49-59. Recuperado em 24 de novembro, 2021, de https://doi.org/10.1037/a0036880. 
Melchert, T. P. (2016). Leaving behind our preparadigmatic past: Professional psychology as a unified clinical science. American Psychologist, 71(6), 486496. Recuperado em 24 de novembro, 2021, de https://doi.org/10.1037/a00402Milton 2010.

Milton, N. R. (2010). A New Framework for psychology. Review of General Psychology, 14(1), 1-15. Recuperado em 24 de novembro, 2021, de https://doi.org/10.1037/a0018325.

Mind (1994). Em Webster's Encyclopedic Unabridged Dictionary of the English Language (p. 1144). Bexley, OH: Gramercy Books.

Nietzsche, F. (2001). O crepúsculo dos ídolos, ou, A filosofia a golpes de martelo (E. Bini, \& M. Pugliesi, Trads.). São Paulo: Hemus (Original publicado em alemão em 1889).

Nöth, W. (1990). Handbook of semiotics. Bloomington, IN: Indiana University Press.

Pavlovic, R. Y. \& Pavlovic, A. M. (2012). Dostoevsky and psychoanalysis: The eternal husband (1870) by Fyodor Dostoevsky (1821-1881). British Journal of Psychiatry, 200(03), 181. Recuperado em 24 de novembro, 2021, de https://doi.org/10.1192/bjp.bp.111.093823.

Peirce, C. S. (1931-1958). Collected Papers (Vols. 1-6, C. Hartshorne, \& P. Weis, Eds.; Vols. 7-8, A. W. Burks, Ed.). Cambridge, MA: Harvard University Press.

Petocz, A. (2011). Re-thinking the place of semiotics in psychology and its implications for psychological research. Em S. C. Hamel (Ed.), Semiotics: Theory and applications (pp. 99-147). Hauppauge, NY: Nova Science.

Petrovski, A. (Ed.) (1985). Psicología geral (Tradutor para o espanhol não informado). Cidade do México: Editorial Progresso. (Original publicado em russo em 1976).

Posinsky, S. H. (1958). Elements of psychology: By David Krech and Richard S. Crutchfield. New York: Alfred A. Knopf, Inc., 1958. 694 pp. Psychoanalytic Quarterly, 27, 426-427. Recuperado em 25 de novembro de 2019 de https://www.pep-web.org/document.php?id=paq.027.0426a.

Radecki, W. (1933). Tratado de psicología (C. Payssé \& V. Delfino, Trads.) Buenos Aires: Casa Editora Peuser Ltda. (Original publicado em português em 1928).

Rancour-Laferriere, D. (Ed). (1989). Russian literature and psychoanalysis. Amsterdam: John Benjamin's Publishing. 
Stanovich, K. E. (2013). How to think straight about psychology. Londres: Pearson Education.

Valsiner, J. (2009). Integrating psychology within the globalizing world: A requiem to the post-modernist experiment with Wissenschaft. Integr Psych Behav, 43(1), 1-21. Recuperado em 24 de novembro, 2021, de https://doi.org/10.1007/s12124-009-9087-x.

VandenBos, G. R. (Ed.). (2015). APA dictionary of psychology. Washington: APA

Wiley, N. (1994). The semiotic self. Chicago, IL: The University of Chicago Press.

Wolman, B. B. (1981). Contemporary theories and systems in psychology. New York: Plenum Press

Wundt, W. (1897). Outlines of Psychology (C.H. Judd, Trans.) Wilhelm Engelmann (Reprinted Bristol: Thoemmes, 1999; Original publicado em alemão em 1896).

Wundt, W. (1916). Elements of folk-psychology: Outlines of a Psychological History of the Development of Mankind (E.L. Schaub, Trans.). Lawrence, KS: Allen. (Original publicado em alemão em 1912). Recuperado em 04 de abril, 2019, de https://archive.org/details/elementsoffolkps00wunduoft/page/xvi.

\section{Nota sobre o autor:}

William Barbosa Gomes é professor aposentado e Fellow Senior do Programa de Pós-Graduação em Psicologia da Universidade Federal do Rio Grande do Sul. Foi Bolsista Produtividade CNPq de 1988 a 2019, onde chegou a Pesquisador 1A entre 2006-2019. Dedica-se, atualmente, a projetos teóricos de longa duração, entre os quais se destacam Diferenças entre Aportes Conceptuais e Estruturais na História da Psicologia, Unidade em Psicologia, e Contribuições da Fenomenologia à Ciência. E-mail:gomesw@ufrgs.br.

Data de submissão: 26.08 .2021

Data de aceite: 30.10 .2021 